\title{
Zur Frage des Vorkommens des Skleralknorpels bei Diemictylus.
}

\author{
Von
}

\author{
Dr. Daisen Osaki.
}

Aus dem Anatomischen Institut der Kaiserlichen Universität zu Kyoto.

Da die Sklera als Schutzapparat des Augapfels eine grosse Bedeutung hat, hat man bisher histolgisch viele Untersuchungen darüber angestellt, indem über das Vorkommen von Knorpel in der Sklera von ausgewachsenem Triton oder Diemictylus die Ansichten noch geteilt sind. Neuerdings hat Tsusaki darüber eine Arbeit veröffentlicht. Ich hatte auch Gelegenheit, eine starke Anzahl von mikroskopischen Präparaten der Diemietylusaugen zu untersuchen und bekam ein von Tsusaki etwas abweichendes Resultat. Dieses werde ich hier kurz beschreiben.

Betreffs der Literatur haben Stad tmüller und Tsusaki eingehende Angaben gemacht; ich konnte auch die meisten Originale berücksichtigen. Man bestätigt einstimmig, dass der Knorpel in der Sklera der meisten Urodelenaugen vorhanden ist, und zwar bei Sieredon (Carrière), Proteus (Leydig, Bronn, Carrière, Kohl, Kallius, Lauber, Franz), Cryptobranchus (Schmidt, Goddart, und V. d. Hoeven, Carrière, Rejsck, Lauber, Franz), Amblystoma (Carrière, Stadt-müller), Hynobius (Okajima und Tsusaki) und Onychodactylus (Okajima), während er bei Salamandra (Bronn, Lauber, Kallius, Pütter, Stadtmüller) nicht gefunden ist. Aber das Vorkommen des Knorpels bei Triton und Diemictylus bleibt bis jetzt noch nicht endgültig entschieden. Carrière (1885) hat den Knorpel in dem Skleralgewebe bei Triton spec. nachgewiesen, während Pütter (1912) diese Angabe in Abrede gestellt hat. Lauber.(1902) behauptet das Fehlen des Knorpels beim Triton cristatus und Stadtmüller (1914) auch beim Triton spec., Tsusaki (1922) hat dagegen den Knorpel bei 3 Fällen (12,5\%) unter 24 Augen von Diemictylus pyrrhogaster gefunden.

Ich habe mikroskopische Präparate von 312 Diemictylus-pyrrhogasteraugen untersucht, die mir, zu anderem Zwecke schon verfertigt, zur Verfügung gestellt wurden. Als Fixierungsmittel sind Formolalkohol 
Daisen Osaki,

und Zenkersche Lösung angewendet; Einbettung in Paraffin und alle quer in $10 \mu$ dicke Serien geschnitten; Färbung mit Hämatoxylin-eosin. Als Kontrolle habe ich noch 14 Paar Augen von Diemictyluslarven (Körperlänge 6-22 $\mathrm{mm}$ ) untersucht. Also bin ich davon fest überzeugt, dass mein Material an Zahl recht genügend ist und ich demgemäss für die Lösung dieser Frage in vortrefflicher Lage bin. Nun habe ich vorsichtig alle Präparate eines nach dem andern durchgemustert und konnte unter 312 Fällen keinen einzigen finden, wo der Knorpel in der Sklera vorhanden war. Bei den Larven von 6 bis $13 \mathrm{~mm}$ Körperlänge konnte ich keinen Skleralknorpel nachweisen, während ich bei den übrigen von mir untersuchten Larven ihn bemerkte; dieser Larvenbefund stimmt gut mit dem von Tsusaki überein. Also kann davon keine Rede sein, dass ich etwa vorhandenen Knorpel in der Sklera der ausgewachsenen Tiere übersehen habe, geschweige denn dass alle Präparate in Serien geschnitten und doppelt gefärbt waren. Ich möchte daher behaupten, dass der Knorpel in der Sklera bei erwachsenem Diemictylus pyrrhogaster fehlt. Natürlich setze ich darin keinen Zweifel, dass Tsusaki in seinen Präparaten tatsächlich den Knorpel beobachtet hat. Wie kann man nun diese abweichenden Resultate erklären? Nach Meiner Meinung soll es hier zwei mögliche Erklärungsweisen geben.

1) Das mir verfügbare Material besteht aus den Augen, die nach Ausführung einer Operation, wie Iridektomie, Linsenextraktion, intraokulare Gewebstransplantation u. s. w., fixiert sind. Wird sich nicht wegen dieses Eingriffs der Knorpel, der im normalen Zustande vorhanden war, zurückbilden?

2) Mein Material stammt aus Kyoto her, während Tsusaki es vielleicht in der Tokyogegend bekommen hat. Sind die Exemplarenicht mehr oder weniger örtlich verschieden?

Die erste Möglichkeit kann man ruhig ausschliessen, weil das operierte Auge, ausser an der direkt angegriffenen Stelle, ganz normal aussieht und man besonders an der Sklera, welche eine dicke, feste Bindegewebeskapsel darstellt, etwaigen Rückbildungsprozess als Folgeerscheinung der Operation nicht annehmen kann. Die zweite Erklärung scheint auch unwahrscheinlich zu sein; der Systematiker kennt zur Zeit im eigentlichen Japan nur eine Art von Diemictylus. So kann ich keinen treffenden Aufschluss finden. Wie es auch sein mag, so muss, wenn ich aus meinem Resultate allein schliessen darf, gewöhnlich der Knorpel in der Sklera der ausgewachsenen Diemictylusaugen fehlen. 
Herr Prof. Dr. Ch. Ogaw a besass die grosse Güte, mich bei dieser Arbeit freundlichst zu beraten, wofür ich ihm auch an dieser Stelle meinen ergebensten Dank aussprechen möchte.

\section{Literatur.}

1. Stadtmüller, F., Ein Beitrag zur kenntnis des Vorkommens und der Bedeutung hyalinknorpeliger Elemente in der Sklera der Urodelen. Anat. Hefte. Bd. 51, 1914.

2. Tsusaki, T., Zur Morphologie des Skleralknorpels von Diemictylus pyrrhogaster. Folia Anatomica Japonica. Bd. I, 1922.

Das ausführliche Literaturverzeichnis ist in diesen beiden Arbeiten angegeben. 